\title{
Theory and Practice in Digital Behaviour Change: A Matrix Framework for the Co-Production of Digital Services That Engage, Empower and Emancipate Marginalised People Living with Complex and Chronic Conditions
}

\author{
Lars Kayser ${ }^{1, * \mathbb{D}}$, Christian Nøhr ${ }^{2}$, Pernille Bertelsen ${ }^{3}$, Lars Botin ${ }^{3}$, Sidsel Villumsen ${ }^{2}$, \\ Chris Showell ${ }^{4}$ and Paul Turner ${ }^{4}$ \\ 1 Health Informatics \& Innovation, University of Copenhagen, DK-1353 Copenhagen, Denmark \\ 2 Maersk Mc-Kinney Møller Institute, University of Southern Denmark, DK-5230 Odense, Denmark; \\ cn@mmmi.sdu.dk (C.N.); sivi@mmmi.sdu.dk (S.V.) \\ 3 Danish Centre for Health Informatics, Aalborg University, DK-9000 Aalborg, Denmark; \\ pernille@plan.aau.dk (P.B.); botin@plan.aau.dk (L.B.) \\ 4 eHealth Services Research Group (eHSRG), University of Tasmania, Tasmania TAS-7001, Australia; \\ cmshowell@gmail.com (C.S.); paul.turner@utas.edu.au (P.T.) \\ * Correspondence: $1 \mathrm{k} @$ sund.ku.dk
}

Received: 10 September 2018; Accepted: 5 November 2018; Published: 9 November 2018

\begin{abstract}
Background: The WHO framework on integrated people-centred health services promotes a focus on the needs of people and their communities to empower them to have a more active role in their own health. It has advocated five strategies including: Engaging and empowering people and communities; co-ordinating services within and across sectors; and, creating an enabling environment. Any implementation of these strategies needs to occur at individual, community, and health service levels. Useful steps to reorganising health service provision are already being guided by existing models of care linked to increased adoption and use of digital technologies with examples including: Wagner's Chronic Care Model (CCM); Valentijn's Rainbow Model of Integrated Care (RMIC); and Phanareth's et al.'s Epital Care Model (ECM). However, what about individuals and the communities they live in? How will strategies be implemented to address known inequities in: the social determinants of health; access to, and use of digital technologies, and individual textual, technical, and health literacies? Proposal of a matrix framework: This paper argues that people with complex and chronic conditions (PwCCC) living in communities that are at risk of being under-served or marginalised in health service provision require particular attention. It articulates a step-by-step process to identify these individuals and co-produce mechanisms to engage, empower and ultimately emancipate these individuals to become activated in living with their conditions and in their interactions with the health system and community. This step-by-step process focuses on key issues related to the design and role of digital services in mitigating the effects of the health service inequity and avoiding the creation of an e-health divide amongst users when advocating digital behaviour change initiatives. This paper presents a matrix framework providing a scaffold across three inter-related levels of the individual; the provider, and the health and care system. The matrix framework supports examination of and reflection on the design and role of digital technologies in conjunction with pre-existing motivational instruments. This matrix framework is illustrated with examples from practice. Conclusion: It is anticipated that the matrix framework will evolve and can be used to map and reflect on approaches and practices aiming to enrich and stimulate co-production activities supported by digital technology focused on enhancing people-centred health services for the marginalised.
\end{abstract}


Keywords: complex chronic conditions; health informatics; engaged; empowered; emancipated

\section{Introduction}

Many of those promoting the role of health informatics for enhancing individual and social health outcomes recognise the importance of engaging 'end-users' for supporting improved design, adoption, and impact of health information systems, applications, and services [1]. Similarly, advocates for more integrated care increasingly promote programs and activities that educate and engage patients and their carers' as 'co-creators' to improve health outcomes [2]. Involving 'end-users' however, especially when patients, continues to prove difficult to implement in practice. For those people living with complex and chronic conditions (PwCCCs) this situation is especially challenging. As 'end-users' these individuals usually require prolonged and heterogeneous interactions with multiple parts of the health care system that frequently impose treatment regimes that many find challenging and that impose a "burden of treatment" [3]. Perhaps unsurprisingly, the challenges faced by PwCCCs has led to numerous theories, models and practices to try to 'engage' these 'end-users' and to support them to more effectively self-manage including through the use of digital services [4,5]. Importantly, many of the advocated approaches have had success in engaging many PwCCCs to become more activated in their own health and to deliver positive benefits in terms of life-style and health outcome measures over time.

Significantly however, it has been noted that amongst the population of PwCCCs, there are many individuals whose personal and social circumstances have contributed to them being marginalised and/or excluded from many types of 'end-user' engagement initiatives [6]. From a health informatics perspective, this has often led to their needs and requirements not being meaningfully incorporated into technology supported chronic disease management initiatives. This is a major concern as frequently these individuals are amongst the most socially disadvantaged in society and they tend to experience poorer health outcomes and cost more per capita from their interactions with the health care system than 'average patients' [7]. More worrying, is the insight that many implicit assumptions about patients, their needs and values embedded within the design of many digital services are unintentionally contributing to a widening of the gap between ordinary and disadvantaged patients and a reinforcement of existing health and e-health inequalities [8].

In this context, this paper aims to contribute to design matrix framework for digital applications, tools and techniques that will contribute to enhanced integrated health care for PwCCCs including consideration of traditionally under-served or marginalised individuals and communities. The framework is structured in a matrix providing a scaffold across three inter-related levels of the individual; the provider; and, the health and care system. The matrix framework supports examination of and reflection on the design and role of digital technologies in conjunction with pre-existing motivational instruments. Drawing on multi-disciplinary practices and experiences from the disciplines of medicine, computer science and the social sciences this paper illustrates how disadvantaged and/or traditionally marginalised individuals can participate in and co-produce their own transitions from being excluded to becoming engaged, empowered and emancipated (4E) in relation to the their own health. The approach specifically targets processes and activities that first identify and then subsequently support disadvantaged PwCCCs more active participation in transitioning towards enhanced involvement in their own health. It is anticipated that this framework will also have benefits for the health system and for the design and delivery of more equitable digital health behaviour change initiatives. More broadly, it is anticipated that the framework as presented in the 4E matrix will both serve as a template for design and a checklist and tool for planning evaluations of digital services supporting PwCCCs. Similar to the technology readiness levels [9], the 4E matrix provides an approach for mapping the readiness of users and assists service designers and service providers to 
understand at which steps in the transition from excluded to emancipated the target groups' needs are supported and the role digital services play.

The next section introduces the concepts of exclusion, engagement, empowerment, and emancipation that are central to the framework structured in the 4E matrix for the co-production of digital health behaviour change interventions.

\section{From Excluded to Engaged}

In order to identify and support disadvantaged PwCCCs to transition towards enhanced involvement in their own health, one needs to understand, who the excluded are and where to find them.

"If one is truly to succeed in leading a person to a specific place, one must first and foremost take care to find him where he is and begin there" [10].

The disadvantaged, disengaged, and disconnected (DDDs) [11] tend to be individuals who have few formal qualifications and limited education, they also tend not to enrol or be recruited into initiatives developing new models of health service delivery. Following Tudor Hart's 'Inverse Care Law' these DDDs are often individuals living in communities of high need and conventionally have poorer health outcomes than the average from their interactions with the health care system [12]. While the category DDDs is a deliberately provocative and extreme archetype of health consumers' sub-optimal interactions with the health care system, it is useful for conceptualising how disadvantage and exclusion may interact with health and e-health initiatives in contemporary society. Amongst those PwCCCs are a wide variety of different types of 'users'. Some are already active and empowered in their own health, some have yet to be engaged but have personal and social circumstances conducive to engagement, while many other individuals have personal and social circumstances that have contributed to them being consistently marginalised, and/or excluded from many types of health and e-health 'end-user' engagement initiatives. This continuum of causes and underlying resources must be understood. Transitioning from exclusion to engagement must ensure any individual potentialities are recognised, capitalised on, and realised in co-production processes. This may mean changing contexts and opportunities, including expanding social networks and/or relieving the burden of treatment [3].

"... all true helping begins with a humbling. The helper must first humble himself under the person he wants to help and thereby understand that to help is not to dominate but to serve, that to help is not to be the most dominating but the most patient, that to help is a willingness for the time being to put up with being in the wrong and not understanding what the other understands" [10].

Drawing on Kierkegaard, engagement can be viewed as a 'formal promise' made between individuals or groups to communicate and interact (Online Etymology Dictionary). In the health care domain engagement usually denotes commitment to open and balanced communication between actors. The processes of engagement are, by their very nature, a co-production between two or more actors that, when successful, involve mutual rights and responsibilities. According to Kierkegaard the 'helper' and the 'recipient of help' are engaged in a mutual 'formal promise' of improving the state of things. It is, therefore, inappropriate (and even unjust) to approach health behaviour change as either solely the patient's or the health professional's responsibility, rather the approach must be reciprocal and formalized in interactions supported by all participants.

Identifying new ways to pro-actively include and meaningfully interact with traditionally marginalised or under-served PwCCCs is difficult and complex. It also requires critical reflection on how inclusive contemporary approaches are that claim to support integrated people-centred digital health behaviour change for PwCCCs [13-15]. Finding new ways of thinking about, identifying and initiating interaction with marginalised PwCCCs involves recognising that some of these individuals may not even be in regular contact with caregivers or health professionals. Approaches must endeavour 
to find these individuals in their own locations and communities, particularly those individuals with few resources and/or weak social and community networks $[16,17]$. To move these individuals beyond their health and social conditions being experienced merely as the burden of disease [18] it is necessary to explore the use of persuasive techniques [19-21], of 'nudging' [22,23] and of interactive gaming tools $[24,25]$. Simultaneously with the deployment of these approaches, there is a need to consider and respond to the extent to which low levels of textual, technical, and health literacy act as barriers to inclusion and to the establishment of interactions that build trust and motivation amongst these individuals and communities [26-29].

Of course, the idea of improving systems and technologies by responding to user resistance or rejection is not new. There is considerable evidence within technology studies and information systems research on how engaging with user resistance to technology has benefits for improving these systems over time [30,31]. Across technology supported design, implementation, and evaluation, co-creation points to ways of opening up the possibility of new dialogues between patients, health professionals and health informaticians to explore key dimensions of the challenges faced. For marginalised PwCCCs involvement in digital health behaviour change initiatives must recognise that challenges include:

(i) Finding effective triggers to stimulate social inclusion and initial user engagement and participation in e-health interventions [32];

(ii) Identifying new modes of communication that address information stickiness, health and digital health literacy and aid user interest in sustained behavioural change [33]; and

(iii) Implementing persuasive user experiences that enhance adoption and sustained use of interventions over time and facilitate transitions from exclusion to engagement through to empowerment and emancipation for marginalized PwCCCs [19,20].

\section{From Engaged to Empowered}

As discussed above, approaches advocating engagement and empowerment of patients (and/or their carers) to participate directly in their own care as a means of improving disease treatment, management and education has been a central theme in the health informatics literature for more than a decade [34]. Experiences from the USA, Australia, and Northern and Southern Europe have reported benefits from involving people with chronic diseases by educating and supporting them to self-manage their conditions using elements of Wagner's chronic care model (CCM) [18,35,36]. More broadly, recognition of the need to generate approaches that involve patients and enable them to better understand and participate in the management of their acute and chronic conditions has been well documented in the health care literature since the 1960s [37,38].

Underpinning this advocacy are assumptions that 'patients' are both capable and willing to take on these new roles and responsibilities and, that being more actively involved will be positive in terms of quality of care and health outcomes [39]. However, it is also known that differentials in health and e-health literacy influence the range and depth of benefits that accrue to participants in digital health behaviour change initiatives. This suggests that there is a need for a more nuanced understanding of empowerment in relation to health and digital health initiatives. In this regard, a new understanding of health-related empowerment is proposed that draws on a Delphi research process amongst participants in the European Innovation Partnership for active and healthy aging [40]. This description states that:

"Empowered individuals are able to and motivated for taking action(s) in daily life to the extent that they wish to do so, to improve their health and well-being. A necessary prerequisite is that they are health literate, i.e., have the knowledge and competencies to manage their health and well-being, they are self-aware and can choose to be involved in the co-management of their health, and able to adjust their health-related behaviour if meaningful for them.

Health-related empowerment interventions aim to equip individuals and their caregivers whenever appropriate with the capacity to collaborate in decisions related to the condition to the extent that 
they wish and are able to do so; to enable co-management of the condition; through mutual agreement between the individuals and their formal and informal caregivers; and to develop the individuals confidence and coping skills, enabling them to manage the physical, emotional and social impacts of their condition that affects their everyday life.

Empowering interventions foster the development of health literacy among staff and the people that they serve." [40].

This new understanding of health related empowerment describes both the relation to formal and informal caregivers and the role of health literacy. It addresses the three inter-related levels of individuals, providers, and the health system thereby supporting enhanced understanding both of how empowering activities can be developed and provides an understanding of in which areas digital tools and services can support individuals. It may also contribute to new approaches to supplement the existing ways to assess empowerment [41].

For designing and planning initiatives, self-determination theory [42], the self-concordance model [43], and trans-theoretical models of behaviour change [44] have all provided fertile ground for a large body of published research on both health and e-health interventions aimed at supporting self-management and positive lifestyle changes amongst a diverse range of users [4,5]. Recently, digitalization of Zoffman's Guided Self-determination Model (GSD) has also opened up additional ways to develop individual empowerment by simultaneously addressing health literacy, motivation, self-awareness, and the development of coping skills and strategies $[45,46]$.

\section{From Empowered to Emancipated}

When PwCCCs have become empowered and are able to actively engage with digital health behaviour change initiatives, opportunities for reflection on their situation, actions, and outcomes may be stimulated. Simultaneously there are opportunities at the provider and health system levels for clinicians and health informatics specialists to reflect on the nature and limits to their on-going roles and interventions. The transition to being emancipated in this context is inspired by the German sociologist and philosopher Jürgen Habermas coining of the term in his early works from the 1960s [47].

For Habermas, emancipation is about how, as individuals, we may use reflection about our own and other's situations and practices to improve our actual conditions. This transition from empowered to emancipated highlights the extent to which we are all capable of reflecting independently on our social, cultural, and individual situations. However, it also acknowledges that this capacity is likely to lead to outcomes that will be drastically different across individuals and groups because actions based on reflection are themselves contingent on individual and community contexts, circumstances and resources [48].

As discussed in the previous sections on the nature of transitions from exclusion to engagement, and engagement to empowerment, it should not be assumed that any effects will be homogenous. This is not about a 'one-size fits all' approach to digital health behaviour change, rather it is about co-production to achieve awareness and activation in terms negotiated with, and for PwCCCs. In this sense, reflections made by marginalized PwCCCs may not automatically lead to positive changes in their life conditions, behaviours, or health outcomes. Rather, it is anticipated that the tools and techniques deployed as part of the empowerment activation process may gradually contribute a kind of awareness and attention towards their potential to change. This awareness and attention may, in the end, build the kinds of determination and resilience that is required to transition from the actual constraining and oppressing societal and institutional procedures and regulations the marginalized face to move towards engagement, empowerment, and emancipation.

The activities and tools that contribute to this type of emancipation focus on supporting self-reflection especially within and between the individual and provider levels of the matrix framework. The aim being to ensure co-production of processes that directly support freedom to act and navigate [49-51]. 


\section{Readiness for Transitioning}

The transitions described above from excluded to engaged, on through empowerment to emancipation can be viewed as a stepwise model of readiness for health transitions that must be considered by any design or intervention advocating a role for technology in supporting PwCCCs.

Figure 1 illustrates how PwCCCs may be differentiated in relation to resources, knowledge, skills, attitudes and in their capacity to be activated along the trajectory of health transitions. This figure highlights an important distinction at the boundary between excluded and engaged that illustrateshow individuals that already have an established diagnosis and regular interactions with health professionals are 'in' the system. The processes for identifying and including traditionally excluded, marginalized or under-served individuals must, therefore, be an integral part of design considerations for any digital health behaviour change initiative, otherwise the "DDDs" are automatically made invisible [52]. Once individuals have transitioned to the engaged state, it is evident that differentials in individual levels of knowledge, competences and skills continue and these directly contribute to how effectively benefits accrue in their efforts to become more involved in their own care and in their efforts to transition to become empowered and/or emancipated as self-managers.

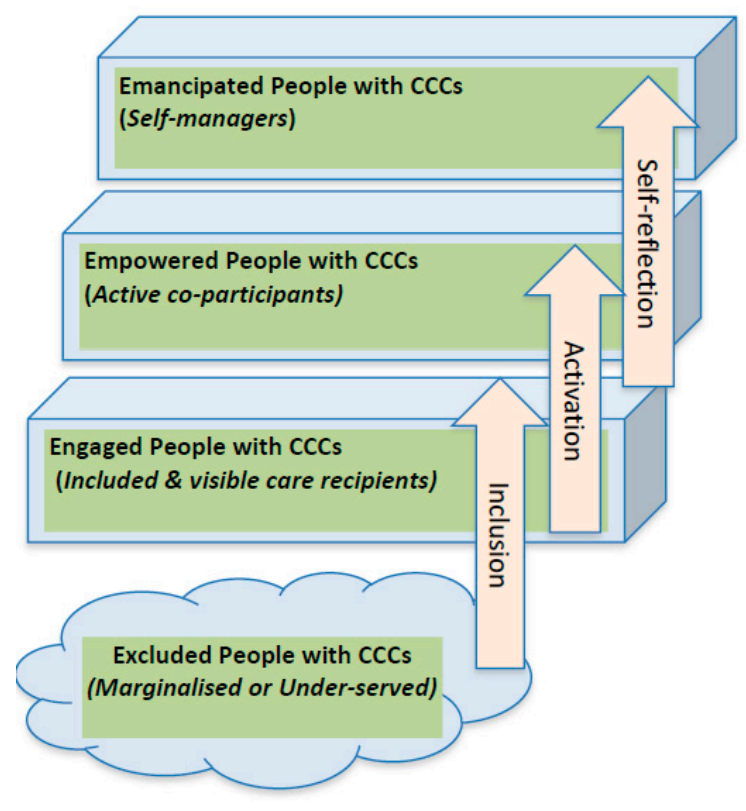

Figure 1. Locating People Living with CCCs in the trajectory of health transitions.

Participants in the engaged phase are usually encouraged to adhere to and comply with service delivery models. They also often tend to exhibit relatively low levels of self-efficacy for self-management. At this basic level of engagement individuals tend to be highly reliant on the service delivery and may exhibit limited personal resources, knowledge of their own condition and/or awareness of how and why the health care system works in the way it does. In order to transition through this engagement phase and move towards the empowered phase, participants need to become activated. They need to be supported with tools and methods to enhance their position in relation to the system, social networks and their personal health conditions. This involves co-production and/or adaption of processes, tools, and techniques that enhance social inclusion. It also means the development of social structures in relation to formal and informal caregivers and/or mechanisms to enhance individuals' capacity to achieve higher levels of health and e-health literacy. As participants become more engaged and increase their capacities and capabilities the opportunity for personal change and transformation of attitude and behaviour in managing their CCCs in collaboration with their health and care providers is advanced towards empowerment. Transitioning from empowerment to the emancipation phase involves self-reflection and in-depth knowledge of one's own health condition, high levels of health and e-health 
literacy, and a detailed understanding of the "how's" and "why's" of the system. True emancipation can only occur through communication where there is a genuinely balanced dialogue such that the system can 'step back' in order for the citizen to realize their own level of emancipation as a PwCCC.

\section{Co-Production of Digital Health Behaviour Change Services: The 4E Matrix Framework}

This section of the paper presents the matrix framework for enhancing the co-production of digital health behaviour change services by targeting marginalised PwCCCs.

Based on the arguments presented in this paper, there are at least three key areas that the designers of digital health behavior change interventions need to address in order to ensure inclusion and activation of marginalized PwCCCs. The first area relates to 'presumptions about patient commitment'. If PwCCCs choose not to enrol in, or are not recruited into, initiatives developing new models of health service delivery what happens? Does their non-participation go unnoticed or unrecorded? Are they deliberately excluded because they fall into the 'too hard' basket within system constraints? When methods, tools and techniques do not fit with, (or fail to respond directly to), what motivates and drives the habits and behaviours of these marginalised individuals in their everyday lives, and/or the factors that shape their social relations and contexts-Are we really surprised about their willingness, interest or commitment to be engaged?

The second area relates to 'presumptions about patient aspirations'. PwCCCs are often unintentionally marginalized by pro-active efforts within many health system initiatives to engage, educate and empower patients to improve their capacities to more actively participate in care delivery processes [53]. The premise of many of these initiatives is that all patients aspire to improve themselves and their health. However, even amongst more literate patients there is evidence that this aspiration is far from universal $[54,55]$. The result is that either the patients do not engage, or if they do, they acquire less benefit over time from participation because initiatives are designed, structured, and delivered with underlying presumptions about their aspirations [56]. The challenge for designers is to reflect on, not just how and to what extent their approaches engage and empower, but beyond that how their approaches actively seek out the disenfranchised and learn how to co-produce approaches that overcome or mitigate existing inhibitor factors and contribute directly to reducing health inequities.

The third area relates to 'presumptions about patient-centeredness'. Almost all contemporary efforts involving patients, pay lip-service to being 'patient-centred' or supporting 'patient empowerment'. Unfortunately, the terms have become so widely used that it has become difficult to work out what patient-centeredness involves and how it can be achieved [57]. Beyond this, it can be argued that almost all approaches are primarily about 'redesigning' patients to fit with the health and e-health system offerings rather than primarily redesigning and tailoring health and e-health service offerings to the needs, capabilities and contexts of patients.

Figure 2 presents a simplified view of the three key dimensions that should be involved in digital health behaviour change initiatives that target marginalized PwCCCs. The level of interaction being supported highlights how and to what extent individuals, health providers, and the health system are supported. At the level of the individual consideration of differences in individual, personal, and social contexts and how these must be recognized and accommodated to ensure that the excluded are enfranchised is key. At the level of the provider consideration of the nature and type of interactions that occur with health and care providers and how these can be enhanced to optimize equity during interaction are key. At the level of the health system consideration of interactions involving health services and technologies must be designed to support all patients and health professionals to be able to easily and seamless interact is key. The phases of transformation in PwCCCs capacity to self-manage highlights consideration of the goals of the digital service-How and to what extent does the service facilitate individuals in their interactions with health professionals and the health system to address social inclusion, activation and self-reflection? Simultaneously, these phases should also stimulate thinking about changes that health professionals and the health system may need to make to optimize these co-produced transformations. The design, implementation, and evaluation of new and existing 
digital applications, tools, and techniques involves reflection on co-production processes and activities and the criteria used by technology designers to measure their success [58].

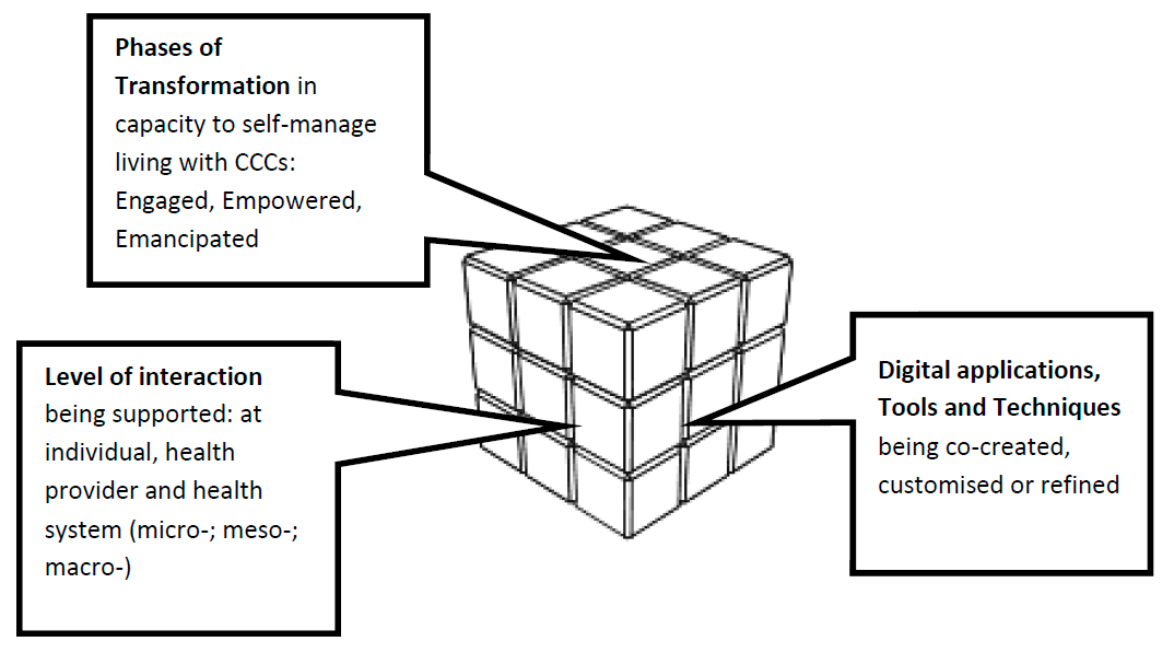

Figure 2. Considerations for the co-production of digital health behaviour change initiatives.

Table 1 presents the 4E matrix framework model linking levels of interaction (individual; provider; Health System) with domains of transformation (excluded, engaged; empowered; emancipated) by individuals, health professionals and the health systems in terms of capacity to successfully manage complex and chronic conditions of all citizens. At the intersection of these elements are key considerations for the processes deployed to support the design, implementation and evaluation of technologies, applications and services. Fundamental to this matrix model is its advocacy for pro-actively seeking out the marginalised PwCCCs 'to find him[her] where he[she] is and begin there'. Conceptually this means moving beyond conventional approaches to PwCCCs to widen our focus to social inclusion, activation, and initialisation of self-reflection by combining digitally-assisted methods and tools for the individual, health care providers, and the health system.

To explore the use of the $4 \mathrm{E}$ matrix model in more detail it is helpful to return to consider the two ways it is anticipated that the model can be utilized. Firstly, a key set of inter-relationships and techniques exist around finding and activating under-served and/or marginalised individuals to overcome their prevailing social exclusion from conventional technology supported self-management interventions. At a basic level, the question arises as to how should these individuals, who do not want to engage, can be identified and enfranchised? As Table 1 indicates at the individual level finding ways to transition across the gap from social exclusion to engagement requires new approaches. One set of new approaches can operate across the different levels and are illustrative of a way forward e.g., Fun theory, Nudging, and Social determinants of Health (SDOH) methods. The examples included in the table are not exhaustive or systematic, rather they highlight examples of some work that is directly trying to grapple with marginalisation and health inequities that can be adapted to digital health behaviour change interventions. For design purposes, the $4 \mathrm{E}$ matrix is presented to assist health and health informatics professionals in their projects to map the intended transitions of PwCCCs and to support them to reflect on how their interventions transform service delivery and the health system as a whole in ways that address health care inequity.

In this way, the $4 \mathrm{E}$ matrix may serve for service designers and other health professionals as an inspiration and guide like the Rainbow Model is intended for development of integrated care solutions [59]. 
Table 1. The 4E matrix, a framework for the co-production of digital services for PwCCCs.

\begin{tabular}{|c|c|c|c|c|c|c|c|}
\hline Levels & Excluded & \multirow{4}{*}{ 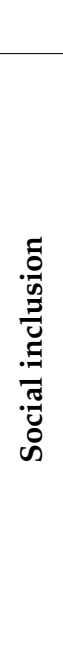 } & Engaged & & Empowered & & Emancipated \\
\hline $\begin{array}{l}\text { Individual } \\
\text { Personal and } \\
\text { social contexts }\end{array}$ & Unattended & & $\begin{array}{l}\text { Pro-active responses tailored } \\
\text { to the attributes and contexts } \\
\text { of DDDs. (e.g., Participatory } \\
\text { Design (PD) Walks; } \\
\text { Fun Theory) }\end{array}$ & \multirow{3}{*}{ 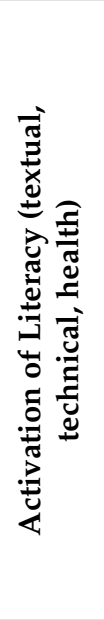 } & $\begin{array}{l}\text { Pro-actively supporting } \\
\text { increased literacy, } \\
\text { self-determination } \\
\text { and empowerment. } \\
\text { (e.g., Guided } \\
\text { Self-Determination) }\end{array}$ & \multirow{3}{*}{ 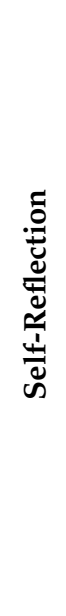 } & \multirow{2}{*}{$\begin{array}{l}\text { Users pro-actively lead choices } \\
\text { of behaviour and lifestyle with } \\
\text { their chronic conditions. } \\
\text { Interactions are user-led and } \\
\text { health professionals become } \\
\text { facilitators of individual } \\
\text { self-management strategies. } \\
\text { (e.g., Wagner, WHO) }\end{array}$} \\
\hline $\begin{array}{l}\text { Provider } \\
\text { Interactions with health } \\
\text { and care providers }\end{array}$ & Unrecorded & & $\begin{array}{l}\text { Social interactions co-designed } \\
\text { through response to DDDs } \\
\text { needs, preferences and } \\
\text { capabilities (e.g., Nudging) }\end{array}$ & & $\begin{array}{l}\text { Social interactions framed to } \\
\text { target empowerment of DDDs } \\
\text { (e.g., Behaviour Change } \\
\text { Support System) }\end{array}$ & & \\
\hline $\begin{array}{l}\text { Health System } \\
\text { System interactions } \\
\text { with health services } \\
\text { and technology }\end{array}$ & Unaware & & $\begin{array}{l}\text { Systems and technologies } \\
\text { designed to pro-actively ensure } \\
\text { inclusion of DDDs. (e.g., SDOH, } \\
\text { HIA and CBPR) }\end{array}$ & & $\begin{array}{l}\text { Health services and technology } \\
\text { re-designed to pro-actively } \\
\text { support DDDs. } \\
\text { (e.g., Picker Institute) }\end{array}$ & & $\begin{array}{l}\text { Health service and technology } \\
\text { innovation led by users } \\
\text { facilitated by the system. } \\
\text { (e.g., Von Hippel; Christensen) }\end{array}$ \\
\hline
\end{tabular}


The examples listed in the Table 1, e.g., Transect Walks or participatory design walks [16] and Fun theories $[60,61]$ are unconventional ways of interacting with the marginalised, socially-disadvantaged PwCCCs that can be deployed for the purposes of first identifying them and their contexts and then for engaging them in co-production of technology supported health behaviour change initiatives. In essence, the aim here is to highlight that individuals who are conventionally marginalised or under-served can be connected with and engaged with if we 'find them where they are'-this implies going to food banks, supermarkets, schools, charities, sporting events, and using both traditional and social media (e.g., TV, Local newspapers, PokemonGo, Facebook, etc.) in ways that are of interest to them. The example of using 'fun' to get people to exercise has already been explored by one of the co-authors of this paper [24,62]. At the provider level techniques like 'nudging' [22] are already beginning to be deployed in transforming health care approaches to behaviour change through choice architectures $[63,64]$. At the health system level there is already a considerable body of knowledge on social determinants of health (SDOH), Health Impact Assessments (HIA), and community-based participatory research (CBPR) with the $4 \mathrm{E}$ matrix advocating for further tailoring of the insights from these approaches to ensure enfranchisement of marginalised PwCCCs. Again, one of the co-authors of this paper has been exploring the use of CBPR in the context of the adoption and use of electronic health records amongst marginalised PwCCCs in rural and remote Australia [65].

\section{Discussion}

The $4 \mathrm{E}$ matrix is the result of a multi-disciplinary collaborative research effort to enhance digital health behaviour change initiatives and ensure that they include and support traditionally marginalised PwCCCs. The matrix framework is intended to ensure clarity in the design and structure of digital services as well as in the nature and type of interactions supported with individuals, health professionals, and the health system. The intention of this paper has not been to make a systematic review or give a comprehensive description of all existing approaches, but rather to offer a template that can be used for planning and development of new inclusive digital health behaviour change initiatives.

The 4E matrix also highlights the organisational level at which activities are implemented and helps to raise an awareness of how an implementation at one level may affect the other levels. For example, the introduction of an application by providers may lead to a need for education or support to individuals and may also require a change of the technological infrastructure to support data gathering which can be shared amongst PwCCCs and their formal and informal care givers.

The $4 \mathrm{E}$ matrix aligns directly with the recent World Health Organization (WHO) vision [66] with the addition of two new aspects (i) the direct targeting and inclusion of marginalised PwCCCs who are not already in contact with the conventional health care system; and, (ii) an outline of the transitions from exclusion to engagement, empowerment and emancipation as an integrated framework in which all 12 quadrants of the matrix need to be considered when planning new ways to provide integrated people-centred digital health behaviour change services.

The $4 \mathrm{E}$ matrix is also a way to understand the readiness and enablement of individuals and how they can best their needs can be met, e.g., through inclusion, activation of literacy, and self-reflection. In this regard, it is acknowledged that considerable work has already been done on instruments that are suitable to aid in identifying where an individual is on this ladder of readiness and enablement. These instruments are grounded in concepts of health behaviour; health literacy and digital health literacy; self-management and coping including: the patient activation measurement Patient Activation Measurement (PAM) [67]; Health education impact Questionnaire (HeiQ) [68]; Health Literacy Questionnaire (HLQ) [69]; and eHealth Literacy Questionnaire (eHLQ) [70]. There is, however, a need to develop an instrument suitable to assess PwCCCs to successfully utilize in a sustained manner digital health behaviour change technologies, applications and/or services. 


\section{A Demonstration of the Use of the 4E Matrix-The Danish Epital Experience}

One example to illustrate how the 4E matrix can enhance contemporary approaches to digital health is provided by an examination of the recently published Epital Care Model (ECM) [71]. The Epital model addresses some of the needs described in the WHO framework for people-centred health-services, i.e., how to empower people, reorganize health services and assist with technologies. However, the ECM requires further modifications to ensure that it identifies and engages marginalised PwCCCs.

For a truly people-centred and inclusive technology supported service provision does need to be designed so that the needs, attributes, and capabilities of the most vulnerable in society are addressed. The $4 \mathrm{E}$ matrix framework may help plan the implementation of ECM by serving as a template and checklist to ensure that the marginalised and underserved will be enabled by suitable methods.

Similarly, by examining the ECM at all three levels in the 4E matrix it is possible to clearly define where and when benefits from technological interventions are appropriate and to be clearer exactly how they are anticipated to deliver value. In the original Epital study [71], only a limited number of marginalised PwCCCs were recruited and at the time it was recognised that it was particularly challenging to recruit even these few individuals. Attempts were made to recruit these individuals in the local community, e.g., when they participated in activities or were out shopping in the local mall but the reality of the resulting recruitment was that the pre-existing level of empowerment as measured by the health education impact questionnaire and health literacy was relatively high amongst those included [72]. Thus, in this particular case, the 4E matrix together with tools such as a digitally-assisted version of GSD [46] will ensure that the Epital Care Model (ECM) will be more inclusive. In its present form, the ECM addresses PwCCCs who are already engaged and often who are also empowered. Additionally, the ECM has been developed with focus on coordination and awareness across the individual and provider levels. The $4 \mathrm{E}$ matrix can be used to both facilitate a dialogue amongst the providers of technical, as well as health services, on how those excluded can be included by taking some of the examples presented above into consideration. Alternatively it may assist in the design of new solutions to identify and include those marginalised and vulnerable individuals. Once these individuals are engaged, the digital assisted GSD method can help those who are difficult to engage with to better understand their own conditions and help them to develop life skills and commence the journey to becoming more empowered. In the case of the ECM, it is anticipated this will be possible through a collaboration with the Danish GSD developer Professor Zoffmann, who has already established the digitally-assisted GSD at the individual, provider, and health system levels. Already individuals, as part of their consultation, can use this tool, at the provider-level there has developed a training for the health professionals, and the Danish health portal sundhed.dk provides the solution at the Regional and probably soon also at the national level. Neither of these cases followed the $4 \mathrm{E}$ scaffold, but as the first author, LK, has been an active partner in the ECM project and has participated in the advisory board of the digital assisted GSD projects, the experiences from these cases have influenced our thinking, and vice versa.

These examples have focused mainly on the vertical integration, but they also demonstrate how a horizontal focus on the individuals progress from excluded to emancipated may help to target the most marginalised PwCCCs.

Integrating a diverse range of approaches will provide a stimulus to improve the whole of the care delivery system by accommodating diversity, facilitating equity and ensuring the integrity and inclusiveness of services delivered. It is anticipated that this will also ensure that future systematic reviews on the impact of digital health interventions on PwCCCs will be able to better differentiate impacts and effects [73].

\section{Conclusions}

This paper has argued that PwCCCs living in communities that are at risk of being under-served or marginalised in health service provision require special attention by health professionals and health 
informatics specialists. The paper has presented a step-by-step process to identify these individuals and to work with them to co-produce mechanisms to engage, empower, and ultimately emancipate them to become activated in living with their conditions and in their interactions with the health system and community.

This step-by-step process focuses on key issues related to the design and role of digital services in mitigating the effects of the health service inequity and avoiding the creation of an e-health divide amongst users when advocating digital health behaviour change initiatives. The $4 \mathrm{E}$ framework matrix aims to provide a conceptual scaffold across three inter-related levels of the individual; the provider; and, the health and care system. The matrix framework supports examination of, and reflection on, the design and role of digital technologies in conjunction with pre-existing motivational instruments.

The framework has been populated with examples from practice and it is anticipated that subsequently the framework will support others to map their approaches and practices to further enrich it and stimulate co-production of activities supported by technology to enhance people-centred health services for the marginalised.

It is anticipated that the framework matrix will support enhanced understanding and visualisation of the connections between planned interventions and the activities, applications, and tools that will facilitate their realisation in practice. Simultaneously the framework provides an approach to characterise the readiness level of the target groups of individuals and act as a stimulus for thinking about how technological approaches enhance current and new ways of delivering equitable health services for all those living with complex chronic conditions.

Author Contributions: The development of the 4E matrix is a collaborative work from L.K., C.N., P.B., L.B., P.T. and S.V. as a result of a retreat session. The first draft was written by P.T. assisted by C.S. A revised version and incorporation of the chronic care and empowerment perspectives was a contribution of the first author L.K. The $4 \mathrm{E}$ matrix framework is inspired by author L.B.'s prior work with his published 7E model. L.K., C.N., P.B., L.B., P.T., C.S. and S.V. have participated in the final revision and all have read and approved the final version.

Funding: No funding was received for this study.

Acknowledgments: Emily Duminski is thanked for helping with preparing the manuscript for the submission.

Conflicts of Interest: None of the authors have competing interests.

\section{References}

1. Kushniruk, A.; Nøhr, C. Participatory Design, User Involvement and Health IT Evaluation. Stud. Health Technol. Inform. 2016, 222, 139-151. [CrossRef] [PubMed]

2. Batalden, M.; Batalden, P.; Margolis, P.; Seid, M.; Armstrong, G.; Opipari-Arrigan, L.; Hartung, H. Coproduction of healthcare service. BMJ Qual. Saf. 2016, 25, 509-517. [CrossRef] [PubMed]

3. May, C.R.; Eton, D.T.; Boehmer, K.; Gallacher, K.; Hunt, K.; MacDonald, S.; Mair, F.S.; May, C.M.; Montori, V.M.; Richardson, A.; et al. Rethinking the patient: Using Burden of Treatment Theory to understand the changing dynamics of illness. BMC Health Serv. Res. 2014, 14. [CrossRef] [PubMed]

4. Michie, S.; van Stralen, M.M.; West, R. The behaviour change wheel: A new method for characterising and designing behaviour change interventions. Implement. Sci. 2011, 6. [CrossRef] [PubMed]

5. Webb, T.L.; Joseph, J.; Yardley, L.; Michie, S. Using the Internet to Promote Health Behavior Change: A Systematic Review and Meta-analysis of the Impact of Theoretical Basis, Use of Behavior Change Techniques, and Mode of Delivery on Efficacy. J. Med. Internet Res. 2010, 12, e4. [CrossRef] [PubMed]

6. Marmot, M.; Allen, J.; Bell, R.; Bloomer, E.; Goldblatt, P. WHO European review of social determinants of health and the health divide. Lancet 2012, 380, 1011-1029. [CrossRef]

7. Coulter, A.; Parsons, S.; Askham, J.; World Health Organization. Regional Office for Europe, European Observatory on Health Systems and Policies. Where Are the Patients in Decision-Making about Their Own care? 2008. Available online: www.who.int/management/general/decisionmaking/ WhereArePatientsinDecisionMaking.pdf (accessed on 10 September 2018).

8. Mackert, M.; Mabry-Flynn, A.; Champlin, S.; Donovan, E.E.; Pounders, K. Health Literacy and Health Information Technology Adoption: The Potential for a New Digital Divide. J. Med. Internet Res. 2016, 18, e264. [CrossRef] [PubMed] 
9. Mankins, J.C. Technology readiness and risk assessments: A new approach. Acta Astronaut. 2009, 65, 1208-1215. [CrossRef]

10. Kierkegaard, S.; Hong, E.H.; Hong, H.V. Kierkegaard's Writings, XXII: The Point of View; Princeton University Press: Princeton, NJ, USA, 2009; ISBN 978-1-4008-3240-8.

11. Showell, C.; Turner, P. The PLU problem: Are we designing personal ehealth for people like us? Stud. Health Technol. Inform. 2013, 183, 276-280. [PubMed]

12. Hart, J.T. The inverse care law. Lancet 1971, 1, 405-412. [CrossRef]

13. Hamine, S.; Gerth-Guyette, E.; Faulx, D.; Green, B.B.; Ginsburg, A.S. Impact of mHealth Chronic Disease Management on Treatment Adherence and Patient Outcomes: A Systematic Review. J. Med. Internet Res. 2015, 17, e52. [CrossRef] [PubMed]

14. Bossen, D.; Veenhof, C.; Dekker, J.; de Bakker, D. The Effectiveness of Self-Guided Web-Based Physical Activity Interventions among Patients with a Chronic Disease: A Systematic Review. J. Phys. Act. Health 2014, 11, 665-677. [CrossRef] [PubMed]

15. Elliot, A.J.; Mooney, C.J.; Douthit, K.Z.; Lynch, M.F. Predictors of Older Adults' Technology Use and Its Relationship to Depressive Symptoms and Well-being. J. Gerontol. B Psychol. Sci. Soc. Sci. 2014, 69, 667-677. [CrossRef] [PubMed]

16. Bertelsen, P.; Kanstrup, A.M.; Madsen, J. Steps toward Technology Design to Beat Health InequalityParticipatory Design Walks in a Neighbourhood with High Health Risks. Stud. Health Technol. Inform. 2017, 233, 158-172. [PubMed]

17. Kanstrup, A.M.; Bertelsen, P.; Madsen, J.Ø. Design with the feet: Walking methods and participatory design. In Proceedings of the 13th Participatory Design Conference, Windhoek, Namibia, 4-10 October 2014; Volume 1, pp. 51-60.

18. Davy, C.; Bleasel, J.; Liu, H.; Tchan, M.; Ponniah, S.; Brown, A. Effectiveness of chronic care models: Opportunities for improving healthcare practice and health outcomes: A systematic review. BMC Health Serv. Res. 2015, 15. [CrossRef] [PubMed]

19. Karppinen, P.; Oinas-Kukkonen, H.; Alahäivälä, T.; Jokelainen, T.; Keränen, A.-M.; Salonurmi, T.; Savolainen, M. Persuasive user experiences of a health Behavior Change Support System: A 12-month study for prevention of metabolic syndrome. Int. J. Med. Inf. 2016, 96, 51-61. [CrossRef] [PubMed]

20. Arnrich, B.; Mayora, O.; Bardram, J.; Tröster, G. Pervasive Healthcare: Paving the Way for a Pervasive, User-centered and Preventive Healthcare Model. Methods Inf. Med. 2010, 49, 67-73. [CrossRef] [PubMed]

21. Fogg, B. A behavior model for persuasive design. In Proceedings of the 4th International Conference on Persuasive Technology, Claremont, CA, USA, 26-29 April 2009; ACM Press: New York, NY, USA, $2009 ;$ p. 1.

22. Halpern, D.; Service, O.; Thaler, R. Inside the Nudge Unit: How Small Changes Can Make a Big Difference; WH Allen: London, UK, 2016; ISBN 978-0-7535-5655-9.

23. Voyer, B. "Nudging" behaviours in healthcare: Insights from behavioural economics. Br. J. Healthc. Manag. 2015, 21, 130-135. [CrossRef]

24. Yee, K.C.; Wong, M.C.; Turner, P. Pokemon Go: Ubiquitous Computing Delivering Better Health or Co-Incidental Health Benefits from Technology Use? A Participatory Observational Study. Stud. Health Technol. Inform. 2017, 234, 389-394. [PubMed]

25. Glasemann, M.; Kanstrup, A.M.; Ryberg, T. Making chocolate-covered broccoli: Designing a mobile learning game about food for young people with diabetes. In Proceedings of the Conference on Designing Interactive Systems, Aarhus, Denmark, 16-20 August 2010; ACM Press: New York, NY, USA, 2010; p. 262.

26. Berkman, N.D.; Sheridan, S.L.; Donahue, K.E.; Halpern, D.J.; Crotty, K. Low health literacy and health outcomes: An updated systematic review. Ann. Intern. Med. 2011, 155, 97-107. [CrossRef] [PubMed]

27. Kayser, L.; Kushniruk, A.; Osborne, R.H.; Norgaard, O.; Turner, P. Enhancing the Effectiveness of Consumer-Focused Health Information Technology Systems Through eHealth Literacy: A Framework for Understanding Users' Needs. JMIR Hum. Factors 2015, 2, e9. [CrossRef] [PubMed]

28. Batterham, R.W.; Hawkins, M.; Collins, P.A.; Buchbinder, R.; Osborne, R.H. Health literacy: Applying current concepts to improve health services and reduce health inequalities. Public Health 2016, 132, 3-12. [CrossRef] [PubMed]

29. Osborne, R.; Kayser, L. Skills and characteristics of the e-health literate patient. BMJ 2018, k1656. [CrossRef] [PubMed] 
30. Morison, E.E. Men, Machines, and Modern Times; M.I.T. Press: Cambridge, MA, USA, 2008; ISBN 978-0-262-13025-7.

31. Kleijnen, M.; Lee, N.; Wetzels, M. An exploration of consumer resistance to innovation and its antecedents. J. Econ. Psychol. 2009, 30, 344-357. [CrossRef]

32. Craig Lefebvre, R.; Tada, Y.; Hilfiker, S.W.; Baur, C. The Assessment of User Engagement with eHealth Content: The eHealth Engagement Scale1. J. Comput. Mediat. Commun. 2010, 15, 666-681. [CrossRef]

33. Elwyn, G.; Taubert, M.; Kowalczuk, J. Sticky knowledge: A possible model for investigating implementation in healthcare contexts. Implement. Sci. 2007, 2. [CrossRef] [PubMed]

34. Warsi, A.; Wang, P.S.; LaValley, M.P.; Avorn, J.; Solomon, D.H. Self-management education programs in chronic disease: A systematic review and methodological critique of the literature. Arch. Intern. Med. 2004, 164, 1641-1649. [CrossRef] [PubMed]

35. Singh, D.; Ham, C. Improving Care for People with Long-Term Conditions: A Review of UK and International Frameworks; University of Birmingham, Health Services Management Centre: Birmingham, UK, 2005; ISBN 0-7044-2584-X.

36. Wodchis, W.P.; Dixon, A.; Anderson, G.M.; Goodwin, N. Integrating care for older people with complex needs: key insights and lessons from a seven-country cross-case analysis. Int. J. Integr. Care 2015, 15. [CrossRef]

37. Scott, K.; Simonds, A. Psychosocial and Cultural Factors Influencing Patient Education. Health Educ. Monogr. 1968, 1, 9-28. [CrossRef]

38. Scott, K. Simonds Health education and medical care: Focus on the patient. Health Educ. Monogr. 1963, $1,32-40$.

39. Cummings, E.; Turner, P. Patients at the centre: Methodological considerations for evaluating evidence from health interventions involving patients use of web-based information systems. Open Med. Inform. J. 2010, 4, 188-194. [CrossRef] [PubMed]

40. Kayser, L.; Karnoe, A.; Duminski, E.; Somekh, D.; Vera-Munoz, C. A new understanding of empowerment in a health context. 2018; submitted.

41. Eskildsen, N.B.; Joergensen, C.R.; Thomsen, T.G.; Ross, L.; Dietz, S.M.; Groenvold, M.; Johnsen, A.T. Patient empowerment: A systematic review of questionnaires measuring empowerment in cancer patients. Acta Oncol. 2017, 56, 156-165. [CrossRef] [PubMed]

42. Ryan, R.M.; Deci, E.L. Self-determination theory and the facilitation of intrinsic motivation, social development, and well-being. Am. Psychol. 2000, 55, 68-78. [CrossRef] [PubMed]

43. Sheldon, K.M.; Elliot, A.J. Goal striving, need satisfaction, and longitudinal well-being: The self-concordance model. J. Pers. Soc. Psychol. 1999, 76, 482-497. [CrossRef] [PubMed]

44. Prochaska, J.O.; Velicer, W.F. The transtheoretical model of health behavior change. Am. J. Health Promot. 1997, 12, 38-48. [CrossRef] [PubMed]

45. Zoffmann, V.; Hörnsten, Å.; Storbækken, S.; Graue, M.; Rasmussen, B.; Wahl, A.; Kirkevold, M. Translating person-centered care into practice: A comparative analysis of motivational interviewing, illness-integration support, and guided self-determination. Patient Educ. Couns. 2016, 99, 400-407. [CrossRef] [PubMed]

46. Rasmussen, B.; Currey, J.; Haigh, B.; Dunning, T.; Zoffmann, V. An online self-management intervention for young adults with type 1 diabetes: Guided Self-Determination program. Aust. Diabetes Educ. 2017, 20, 1-9.

47. Habermas, J.; Shapiro, J.J. Knowledge and Human Interests; Beacon Press: Boston, MA, USA, 1971; ISBN 978-0-8070-1541-4.

48. Botin, L.; Bertelsen, P.; Nøhr, C. (Eds.) Techno-Anthropology in Health Informatics: Methodologies for Improving Human-Technology Relations; Studies in health technology and informatics; IOS Press: Amsterdam, The Netherland; Washington, DC, USA, 2015; ISBN 978-1-61499-559-3.

49. Nohr, C.; Botin, L.; Zhu, X.X. How Can Health Information Technologies Contribute to Improve Health Care Services for High-Need Patients? Stud. Health Technol. Inform. 2017, 241, 28-35. [CrossRef] [PubMed]

50. Pezdek, K.; Rasiński, L. Between exclusion and emancipation: Foucault's ethics and disability. Nurs. Philos. 2017, 18, e12131. [CrossRef] [PubMed]

51. Raymaker, D.M. Intersections of Critical Systems Thinking and Community Based Participatory Research: A Learning Organization Example with the Autistic Community. Syst. Pract. Action Res. 2016, 29, 405-423. [CrossRef] [PubMed] 
52. Showell, C.; Cummings, L.; Turner, P. The Invisibility of Disadvantage: Why Do We Not Notice? Stud. Health Technol. Inform. 2017, 388-392. [CrossRef]

53. Gulbrandsen, P.; Clayman, M.L.; Beach, M.C.; Han, P.K.; Boss, E.F.; Ofstad, E.H.; Elwyn, G. Shared decision-making as an existential journey: Aiming for restored autonomous capacity. Patient Educ. Couns. 2016, 99, 1505-1510. [CrossRef] [PubMed]

54. Fredriksson, M.; Eriksson, M.; Tritter, J. Who wants to be involved in health care decisions? Comparing preferences for individual and collective involvement in England and Sweden. BMC Public Health 2018, 18. [CrossRef] [PubMed]

55. Medibank. Australians Giving up on Living in Good Health. 2014. Available online: https: / / www.medibank.com.au/content/about/media-centre/2014/07/australians-giving-up-on-a-healthylife/jcr\%3acontent/par/download/file.res/MED14005_HEALTH_CHECK_2_FINAL.pdf (accessed on 10 September 2018).

56. Willis, K.F.; Robinson, A.; Wood-Baker, R.; Turner, P.; Walters, E.H. Participating in Research: Exploring Participation and Engagement in a Study of Self-Management for People with Chronic Obstructive Pulmonary Disease. Qual. Health Res. 2011, 21, 1273-1282. [CrossRef] [PubMed]

57. Tomes, N. Patient empowerment and the dilemmas of late-modern medicalisation. Lancet 2007, 369, 698-700. [CrossRef]

58. Kelder, J.; Turner, P. Lost in Translation? Critical Reflection on Qualitative Approaches for Informing Information Systems Design. In Proceedings of the QuallIT2005: Challenges for Qualitative Research, Brisbane, Australia, 23-25 November 2005.

59. Valentijn, P.P.; Schepman, S.M.; Opheij, W.; Bruijnzeels, M.A. Understanding integrated care: A comprehensive conceptual framework based on the integrative functions of primary care. Int. J. Integr. Care 2013, 13, e010. [CrossRef] [PubMed]

60. Åberg, A.; Halvorsen, K.; From, I.; Bruhn, Å.; Oestreicher, L.; Melander-Wikman, A. A Study Protocol for Applying User Participation and Co-Learning_Lessons Learned from the eBalance Project. Int. J. Environ. Res. Public Health 2017, 14, 512. [CrossRef] [PubMed]

61. Visek, A.J.; Achrati, S.M.; Mannix, H.M.; McDonnell, K.; Harris, B.S.; DiPietro, L. The Fun Integration Theory: Toward Sustaining Children and Adolescents Sport Participation. J. Phys. Act. Health 2015, 12, 424-433. [CrossRef] [PubMed]

62. Wong, M.C.; Turner, P.; MacIntyre, K.; Yee, K.C. Pokémon-Go: Why Augmented Reality Games Offer Insights for Enhancing Public Health Interventions on Obesity-Related Diseases. Stud. Health Technol. Inform. 2017, 241, 128-133. [PubMed]

63. Broers, V.J.V.; De Breucker, C.; Van den Broucke, S.; Luminet, O. A systematic review and meta-analysis of the effectiveness of nudging to increase fruit and vegetable choice. Eur. J. Public Health 2017, 27, 912-920. [CrossRef] [PubMed]

64. VicHealth. Behavioural Insights and Healthier Lives; Victorian Health Promotion Foundation: Melbourne, Australia, 2016. Available online: https:/ / www.vichealth.vic.gov.au/media-and-resources/publications / behavioural-insights-and-healthier-lives (accessed on 10 September 2018).

65. Almond, H.; Cummings, E.; Turner, P. Avoiding Failure for Australia's Digital Health Record: The Findings from a Rural E-Health Participatory Research Project. Stud. Health Technol. Inform. 2016, 227, 8-13. [CrossRef] [PubMed]

66. WHO Framework on Integrated People-Centred Health Services, a Report by the Secretariat. Available online: http:/ / www.who.int/servicedeliverysafety/areas/people-centred-care/en/ (accessed on 11 May 2017).

67. Hibbard, J.H.; Stockard, J.; Mahoney, E.R.; Tusler, M. Development of the Patient Activation Measure (PAM): Conceptualizing and Measuring Activation in Patients and Consumers: Development of the Patient Activation Measure (PAM). Health Serv. Res. 2004, 39, 1005-1026. [CrossRef] [PubMed]

68. Osborne, R.H.; Elsworth, G.R.; Whitfield, K. The Health Education Impact Questionnaire (heiQ): An outcomes and evaluation measure for patient education and self-management interventions for people with chronic conditions. Patient Educ. Couns. 2007, 66, 192-201. [CrossRef] [PubMed]

69. Osborne, R.H.; Batterham, R.W.; Elsworth, G.R.; Hawkins, M.; Buchbinder, R. The grounded psychometric development and initial validation of the Health Literacy Questionnaire (HLQ). BMC Public Health 2013, 13, 658. [CrossRef] [PubMed] 
70. Kayser, L.; Karnoe, A.; Furstrand, D.; Batterham, R.; Christensen, K.B.; Elsworth, G.; Osborne, R.H. A Multidimensional Tool Based on the eHealth Literacy Framework: Development and Initial Validity Testing of the eHealth Literacy Questionnaire (eHLQ). J. Med. Internet Res. 2018, 20, e36. [CrossRef] [PubMed]

71. Phanareth, K.; Vingtoft, S.; Christensen, A.S.; Nielsen, J.S.; Svenstrup, J.; Berntsen, G.K.R.; Newman, S.P.; Kayser, L. The Epital Care Model: A New Person-Centered Model of Technology-Enabled Integrated Care for People with Long Term Conditions. JMIR Res. Protoc. 2017, 6, e6. [CrossRef] [PubMed]

72. Lindskrog, S.; Christensen, K.B.; Osborne, R.H.; Vingtoft, S.; Phanareth, K.; Kayser, L. How patient reported outcome measures from heiQ, HLQ and SF-36 can be used to follow people with COPD in an ehealth based 24/7 service, the 'Epital Care Model'. J. Med. Internet Res.. under review.

73. McCabe, C.; McCann, M.; Brady, A.M. Computer and mobile technology interventions for self-management in chronic obstructive pulmonary disease. Cochrane Database Syst. Rev. 2017. [CrossRef] [PubMed]

2018 by the authors. Licensee MDPI, Basel, Switzerland. This article is an open access article distributed under the terms and conditions of the Creative Commons Attribution (CC BY) license (http://creativecommons.org/licenses/by/4.0/). 